\title{
ANALISIS KEERATAN HUBUNGAN DI ANTARA PELANGGAN - KARYAWAN DAN PERUSAHAAN MENGGUNAKAN METODE HUMAN SIGMA (Studi Kasus : Jeng Dewi Wedding Organizer)
}

\author{
Sunaryo ${ }^{1}$, Abdul Kholid ${ }^{2}$ \\ Jurusan Teknik Industri Fakultas Teknologi Industri Universitas Islam Indonesia ${ }^{1,22}$, \\ Jl Kaliurang Km 14,5 Sleman yogyakarta 55584. \\ E-Mail : Sunaryo@uii.ac.id
}

\begin{abstract}
One of the service industry in Indonesia is wedding Organizer. It's operation is fasilitation in wedding fiesta. To increase the volume of operation, the Jeng Dewi Wedding Organizer has to createsquality of services. It can be done by increasing engagements and relations amongs employeecustomer and the company. Engagement amongs of them will be the main factor of the company's sucsess. The customers has to be made satisfied by services. They are not satisfied by rational but olso by emotional. The customers which satisfied by services will results a big profit. To do it coompany has to create a big engagements among of them. It needs an analysis, which can use Human Sigma to measure the value of engagement. Human Sigma is a tool to analyse the person's emotinal. The result of this analysis is 35.5\% for the value Human Sigma, 49 \% for the value of Customers Engagement and $49 \%$ for the value of Employee Engagement. So the corporation has to increase all of this parameter.
\end{abstract}

Keywords : Wedding Organizer, Employee Engangement, Customer Engangement, Human Sigma.

\section{PENDAHULUAN}

Perusahaan jasa yang sedang bermunculan adalah jasa wedding organizer karena bisnis ini begitu menjanjikan dan memiliki peluang besar. Salah satu cara untuk meningkatkan eksistensi perusahaan jasa wedding organizer menciptakan hubungan baik dengan pelanggannya baik secara emosional maupun pribadi. Untuk itu citra suatu wedding organizer harus posistif dimata pelanggan. Citra positif bisa timbul akibat dari persepsi pelanggan terhadap kualitas pelayanan yang baik dari pihak karyawan. Kualitas pelayanan yang baik membuat pelanggan merasa puas sehingga timbul loyalitas pelanggan. Keeratan diantara pelanggan, perusahaan dan karyawan harus dibangun karena melalui hubungan ketiga komponen ini akan menimbulkan ikatan emosional yang baik dan kuat. Emosi karyawan yang merasa nyaman bekerja pada perusahaan akan memberi pelayanan terbaik pada pelanggan. Pelayanan yang diberikan dengan berinteraksi langsung pada pelanggan merupakan salah satu bentuk pelayanan yang cukup mempengaruhi loyalitas pelanggan karena langsung dirasakan oleh pelanggan. Metode untuk mengukur keeratan hubungan pelanggan dan karyawan terhadap perusahaan adalah Metode Human Sigma . Metode ini menggunakan nilai customer engangement dan employee engangement untuk mengetahui nilai human sigma score. Metode Human Sigma adalah sebuah model dan pendekatan yang dikembangkan oleh John h. Fleming, Curt Coffman dan James Harter (2005). Menurut Fleming (2007), di dalam metode human sigma, pelanggan yang memiliki ikatan emosional yang kuat dengan perusahaannya akan menghasilkan share of investable assets yang lebih tinggi dan share of spending yang juga lebih tinggi. Perusahaan yang bergerak di bidang jasa perlu meningkatkan keeratan hubungan antara karyawan ,perusahaan dan pelanggan. Mengetahui nilai Human Sigma (HS), keeratan hubungan pelanggan terhadap karyawan (CE) dan keeratan hubungan karyawan (EE), sebagai bahan evaluasi kinerja pelayanan perusahaan dan dapat 
dijadikan dasar pemikiran strategi perusahaan.

\section{TINJAUAN PUSTAKA}

Analisis keeratan hubungan antara pelanggan dengan karyawan dengan menggunakan metode human sigma telah banyak dilakukan. Pelanggan yang puas secara emosional akan menghasilkan keuntungan yang lebih besar kepada perusahaan.

Untuk mendukung kepuasan pelanggan, hubungan antara pelanggan dan pegawai terhadap perusahaan harus memiliki ikatan emosional yang kuat. Dengan menggunakan human sigma maka perusahaan dapat melakukan evaluasi kinerja perusahaan dan menyusun strategi ke depan. Metode Human Sigma pertama kali diperkenalkan oleh John H. Fleming, C. Coffman dan James K. Harter pada tahun 2005 sebagai model dan pendekatan disertai aturan - aturan baru untuk menilai kualitas interaksi karyawan dan para pelanggan serta aspek pengelolaan dan perbaikan hubungan antar keduanya. Human Sigma fokus kepada emosi dan perilaku manusia meskipun tidak bersifat universal. Karyawan dan pelanggan perlu menjaga hubungan diantara keduanya karena memiliki pengaruh terhadapkinerja dan keberlangsungan jangka panjang perusahaan, karena itu perlu pendekatan secara holistik. Oleh karena itu perencanaan strategi bisnis dalam bentuk pelatihan terpadu, review kinerja, kegiatan pembelajaran terprogram, dan bimbingan individual menjadi sangat strategis untuk dilakukan perusahaan (John H. Fleming dkk, 2005). Terdapat 2 jenis keeratan hubungan pelanggan yang terdapat pada Human Sigma, yaitu puas secara rasional dan puas secara emosional. Pelanggan akan merasakan puas secara emosional apabila pelanggan merasa sangat puas terhadap produk atau jasa sehingga pelanggan mempunyai ikatan emosional yang kuat dengan perusahaan. Sedangkan pelanggan yang puas secara rasional merupakan pelanggan yang sangat puas dengan produk atau jasa akan tetapi sama sekali tidak memiliki ikatan emosional dengan karyawan perusahaan. Pelanggan yang puas secara emosional memberikan manfaat yang lebih besar kepada perusahaan dibandingkan dengan pelanggan yang puas secara rasional, misalnya membeli lebih banyak produk, frekuensi membeli yang lebih sering, tetap loyal terhadap perusahaan , dan lain - lain.

Berdasarkan tingkat emosional terhadap perusahaan terdapat 4 golongan pelanggan (Fleming, 2007), yaitu :

1. Fully Enganged Pelanggan memiliki ikatan emosional yang kuat dan sangat loyal terhadap prusahaan.

2. Enganged, pelanggan belum seutuhnya terbentuk ikatan dengan perusahaan namun telah tebentuk fondasi untuk membentuk ikatan yang lebih kuat.

3. Not Enganged, Pelanggan golongan ini memiliki emosional netral terhadap perusahaan dan tidak loyal dengan perusahaan manapun.

4. Actively Disenganged, Pelanggan ini mempunyai perasaan yang negatif terhadap perusahaandan cenderung membahayakan perusahaan karena bisa mendukung pihak pesaing serta dapat memberikan pengaruh buruk terhadap pelanggan lain.

\subsection{Tingkat - tingkatan Mutu Interaksi dalam Human Sigma}

Human Sigma menggunakan sistem pengukuran kuantitatif dengan menggunakan 4 dimensi ikatan emosional ( Gambar 1).

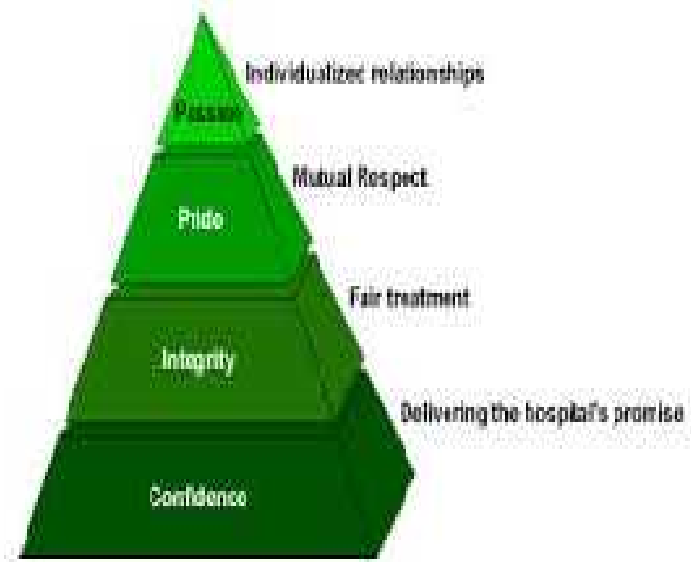

Gambar 1. Piramida Dimensi Ikatan Emosional. (Fleming, 2007) 


\section{Keterangan :}

1. Confidence (kepercayaan pelanggan terhadap perusahaan).

2. Integrity (tingkat konsistensi pelanggan dalam menggunakan produk jasa perusahaan).

3. Pride (tingkat kebanggaan pelanggan terhadap produk atau jasa, atau terhadap perusahaan itu sendiri).

4. Passion (tingkat ketergantungan pelanggan menggunakan produk / jasa).

Dimensi - dimensi diatas digunakan sebagai pengukuran ikatan keeratan .secara kualitatif antara perusahaan dengan pelanggan.

\subsection{Employee Engagement.}

Terdapat 4 dimensi Employee Engagement yang digunakan dalam metode Human Sigma, yang digambarkan kedalam sebuah piramida. Dimensi ini digunakan untuk mengetahui apakah pelanggan merasa telah mendapatkan perlakuan adil dan pelayanan secara professional oleh perusahaan. Level individu menunjukkan bagaimana perusahaan berinteraksi dengan pelanggan secara personal (gambar 2). 4 dimensi Employee Engagement tersebut yaitu :

\section{A. What Do I Get}

Dimensi ini merupakan kebutuhan dasardalam pembentukan ikatan emosional karyawan dengan perusahaan berdasarkan penyediaan sarana prasaranakebutuhan karyawan.

\section{B. What Do I Give}

Dimensi What Do I Give adalah dimensi yang menunjukkan besar kontribusi karyawan (individual contribution) kepada perusahaan.

\section{Do I Belong}

Merupakan dimensi yang menunjukkan karyawan merasa memiliki dan bertanggung jawab terhadap perusahaan.

\section{How Can We Grow}

Dimensi ini lebih mengarah pada peran aktif perusahaan dalam meningkatkan kemampuan dan kompetensi karyawan dalam mencapaiemployeeengagement.
Employee Engagement Hierarchy

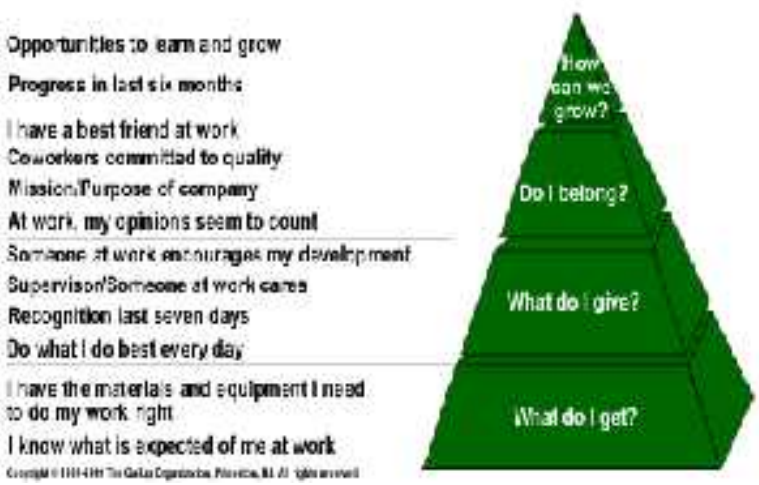

Gambar 2. Piramida 4 Dimensi Employee Engagement. (Sumber : Fleming, 2007).

\subsection{Parameter Employee Engagement}

Untuk pengukuran hubungan karyawan digunakan survey pertanyaan berjenjang dengan urutan sebagai berikut (Fleming, 2007) :

a. Saya tahu apa yang diharapkan dari saya tentang pekerjaan ini.

b. Saya tidak memiliki segala sesuatu untuk melakukan pekerjaan ini dengan baik.

c. Dalam bekerja, saya memiliki kesempatan untuk melakukan yang terbaik setiap harinya.

d. Dalam tujuh hari terakhir, saya mendapat pujian atas hasil kerja say

e. Atasan saya terlihat sangat memperhatikan saya sebagi bawahan.

f. Atasan dan teman - teman saya selalu memberikan dorongan kepada saya untuk selalu lebih maju lagi.

g. Pendapat saya selalu diperhatikan oleh atasan dan teman - teman saya.

h. Tujuan perusahaan yang sudah jelas dan membuat saya merasa dibutuhkan dalam pekerjaan ini.

i. Teman - teman saya memiliki komitmen yang kuat untuk memberikan yang terbaik untuk perusahaan.

j. Saya memiliki teman - teman yang terbaik dalam pekerjaan.

k. Dalam enam bulan terakhir ini seseorang telah memberikan pernyataan bahwa saya mempunyai kemajuan yang positif dalam pekerjaan. 
1. Dalam setahun terakhir, saya mempunyai kesempatan untuk belajar dan berkembang.

\subsection{Parameter Customer Engagement}

Untuk melakukan pengukuran hubungan pelanggan digunakan survey pertanyaan berjenjang dengan urutan sebagi berikut (Fleming, 2007) :

a. Apakah anda menggunakan produk / jasa secara keseluruhan?

b. Apakah anda akan senantiasa menggunakan produk / jasa ini?

c. Apakah anda akan merekomendasikan produk / jasa ini kepada orang lain?

d. Produk ini adalah produk / jasa yang dapat dipercaya.

e. Produk ini merupakan produk / jasa yang sesuai dengan yang dijanjikan.

f. Perusahaan ini selalu mengutamakan kepuasan pelanggan.

g. Produk / jasa ini selalu menjadi solusi kebutuhan saya.

h. Saya sangat bangga memakai produk / jasa ini.

i. Perusahaan ini sellau memperhatikan kebutuhan pelananggannya.

j. Produk ini adalah produk / jasa yang sempurna untuk saya.

k. Saya tidak dapat membayangkan apabila di dunia ini tidak ada produk ini.

\section{METODOLOGI PENELITIAN}

\subsection{Diagram Alir Penelitian}

Untuk menjelaskan mengenai tahap - tahap penelitian ditunjukkan pada Gambar 3 berikut ini.

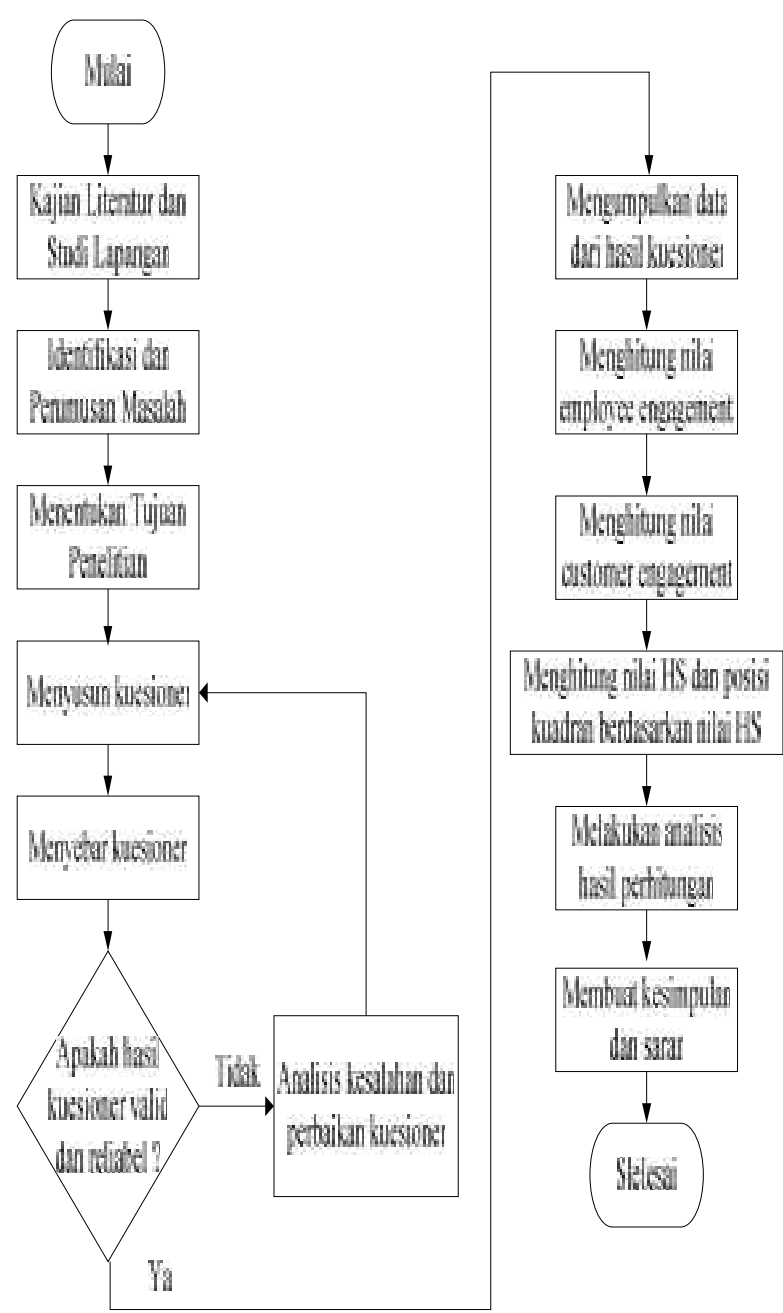

Gambar 3. Flowchart Metodologi Penelitian.

Metode yang digunakan dalam penelitian ini adalah metode Deskriptif kuantitatif, dimana penelitian diarahkan untuk mengurai atau menjelaskan secara rinci ekspektasi (harapan) pelanggan dengan kenyataan pelayanan yang diperoleh dengan menggunakan kuesioner yang bersifat tertutup.

\subsection{Metode Pengumpulan Data}

Teknik pengumpulan data baik data primer maupun sekunder dalam penelitian ini adalah metode kuantitatif. Atau disebut sebagai metode positivistik karena berlandaskan pada filsafat positivisme. Metode ini sebagai metode ilmiah / scientific karena telah memenuhi kaidah - kaidah ilmiah yaitu konkrit / empiris, obyektif, terukur, rasional, dan sistematis. Untuk itu perlu dibuat kuesioner yng perlu diuji kevalidannya 
dengan uji hiptesis dengan menentukan $r$ tabel dengan tingkat signifikansi 5\% derajat kebebasan $(\mathrm{df})=\mathrm{n}-2$ yang dapat dilihat pada tabel-r dan mencari nilai rhitung .Jika nilai rhitung bernilai positif, serta rhitung $\geq$ rtabel maka kuesioner diterima. Demikian juga kuesioner perlu diuji reliablilitasnya untuk mengukur bahwa kuesioner dapat dipercaya dan diandalkan dalam pengukuran berulang kali tetap konsisten (Singarimbun, 1989). Metode yang digunakan dalam menentukan tingkat reliabilitas adalah koefisien Alpha Cronbach, dan dikatakan reliabel jika nilai Croncbach Alpha> 0,7 (Yamin \& Kurniawan, 2004). Perhitungan jumlah sampel n untuk penyebaran kuesioner ditentukan dari rumus Snedecor GW \& Cochran WG (1967) dan Lemeshoxw dkk (1997) adalah sebagai berikut :

$$
\mathrm{n}=\frac{\mathrm{z}_{1-\alpha / 2}^{2} \mathrm{p}(1-\mathrm{p}) \mathrm{N}}{\mathrm{d}^{2}(\mathrm{~N}-1)+\mathrm{Z}_{1-\alpha / 2}^{2} \mathrm{p}(1-\mathrm{p})}
$$

\section{Dimana :}

$\overline{Z_{1-\alpha / 2}^{2}=}$ dengan menggukan derajat kepercayaan sebesar $95 \%$ atau $\alpha=0,05$, maka ditetapkan nilai $\mathrm{z}_{1-x / 2}^{2}=1,96$.

$\mathrm{d}=$ penyimpangan terhadap populasi atau derajat kepercayaan yang diinginkan $10 \%(0,1)$.

$\mathrm{p}=$ proporsi untuk sifat tertentu yang diperkirakan terjadi pada populasi $(0,5)$ dan,

$\mathrm{N}=$ besarnya populasi.

Hasil perhitungan didapatkan sampel kuesioner karyawan adalah 30,86 dan agar lebih akurat dibuat kuisioner sebanyak 40 kuisioner dan didapat 49,24 atau 49 kuisioner pelanggan. Agar lebih akurat dibuat 60 kuesioner pelanggan.Untuk setiap pertanyaan diberikan skala likert 1 hingga satuan nilai tertinggi misalnya 5mulai dari sangat tidak setuju, tidak setuju, netral,setuju dan sangat setuju.

\subsection{Pengujian Validasi Kuesioner Pelanggan}

Uji Validasi kuesioner untuk pelanggan atribut 1 didapat nilai korelasi sebesar 0,403 dengan probabilitas korelasi [sig. (2-tailed)] sebesar 0,001sehingga bsa dikatakan valid, karena nilai korelasi berada diatas kriteria yang berada dalam Distribusi Nilai $r_{\text {tabel }}$ dan memiliki nilai probabilitas korelasi [sig. (2tailed $)<$ dari taraf signifikan $(\alpha)$ sebesar 0,05 . Begitu pula untuk instrument atau pertanyaan kuesioner yang lain. Hal ini menunjukkan bahwa setiap nomor pada kuesioner tersebut adalah valid. Sedang Uji Reliabilitas untuk pelanggan.

Melelui perhitungan software SPSS diatas, nilai alpha croncbach adalah 0,742., lebih besar 0,7, artinya atribut - atribut kuesioner yang diberikan kepada pelanggan sudah reliable.

\subsection{Uji Validitas Kuesioner Karyawan}

Dari dari atribut 1 diperoleh nilai korelasi sebesar 0,617, dengan probabilitas korelasi [sig. (2-tailed)] sebesar 0,000. Sesuai kriteria sebelumnya, instrumen kuesioner atribut 1 adalah valid, karena nilai korelasi berada diatas kriteria yang berada dalam Distribusi Nilai $r_{\text {tabel }}$ dan memiliki nilai probabilitas korelasi [sig. (2-tailed) < dari taraf signifikan ( $\alpha$ ) sebesar 0,05. Begitu pula untuk instrument atau pertanyaan kuesioner yang lain. Hal ini menunjukkan bahwa setiap nomor pada kuesioner tersebut adalah valid.

\subsection{Uji Reliabilitas}

Berdasarkan hasil perhitungan dengan menggunakan software SPSS ,nilai alpha croncbach adalah 0,736 dimana $>0,7$ berarti alat tes kuesioner dengan atribut-atribut sudah reliable. Reliable berarti tingkat konsistensi, keakuratan dan daya prediksi kuesioner yang baik.

\subsection{Metode Analisis Data}

Dalam bukunya John H. Fleming dkk (2007) mengemukakan sebuah metodologi pengukuran yang bersifat kuantitatif yang dikenal sebagai metode Human Sigma Index. Pengukuran Human Sigma menggunakan 2 
pengukuran kuantitatif sebagai input, yaitu : Nilai kuantitatif hubungan karyawan perusahaan atau Empolyee Engagement (EE) dan hubungan pelanggan - perusahaan atau Customer Engagement (CE).

\section{Humphiging =}

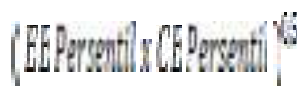

$\mathrm{x}$ (Persentil maks./Persentil min) ${ }^{\mathrm{bij}}$

Rumus di atas digunakan untuk kasus dimana EE Persen dan CE Persen adalah di atas median distribusi. Sedangkan apabila salah satu dari nilai tersebut diatas ada yang kurang dari median distribusi datanya maka menggunakan rumus sebagai berikut :

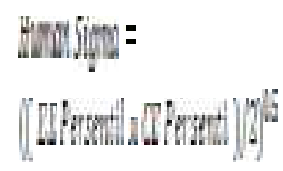

Kuadran dalam Human Sigma terdiri atas 2 tipe, yang dibagi menjadi 4 kuadran dan 6 kuadran. Untuk tipe 6 kuadran dibagi menjadi daerah HS1 sampai HS6. Setiap unit usaha bergerak menuju bagian kanan atas grafik (daerah HS6), business performance 5,2 kali pertumbuhan pendapatan. Hal ini juga mencakup distribusi unit usaha dalam Database Gallup dengan 5\% jatuh ke HS1 (1.0x) dan hanya sekitar 1\% dari unit yang mereka ukur mencapai status HS6. Sekitar $60 \%$ dari unit usaha yang ada di Gallup database yang jatuh ke dalam HS2 dan HS3 di mana performasinya ada di antara 1,8 kali dan 2,5 kali.

Koefisien memberikan dampak yang mencolok bagi nilai kuadran Human Sigma dan tingkat Human Sigma sehingga mendekati fungsi non linear yang kompleks yang disebut sebagai "fungsi phi". Maka dalam Human Sigma ini menjadi.

$\varphi_{H S}=\frac{1+\sqrt{\left(6 k_{H S}+1\right)}}{2}$.

dimana Human Sigma sama dengan tingkat HS (1 sampai 6) dan $\mathrm{k}$ adalah fungsi rekursif.
$k_{H S}=(H S-1)+k_{H S-1} \ldots \ldots \ldots \ldots \ldots \ldots . .(5)$

dimana $\mathrm{k} 1=0$.

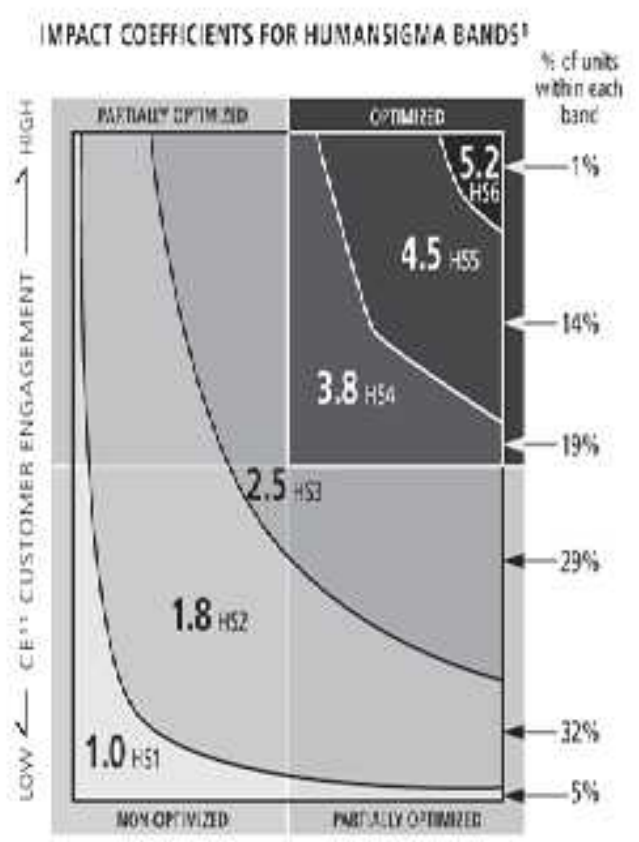

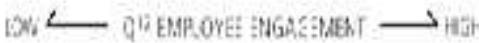

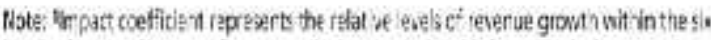

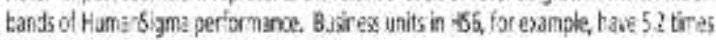

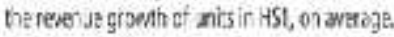

Source: Sallup

Gambar 4. Human Siagma Level Plot 6 Kuadran. (Sumber : Fleming, 2007).

\section{HASIL PENELITIAN DAN PEMBAHASAN}

Nilai Customer Engangement pelanggan dihitung dengan mengurutkan nilai dari setiap pelanggan dari yang terkecil sampai yag terbesar diperoleh :

CE persen $\quad=29,5 / 60=0,49$ atau $49 \%$. Median $\quad=3.526$.

Mean $=3.485$ (lebih kecil dari median).

$\mathrm{CE}$ Index $\quad=($ mean/5) $\times 6=(3.485 / 5)$ x $6=4,182$.

Dapat dilihat bahwa rata-rata dari 60 data yang didapatkan adalah 3, 485. Untuk menghitung nilai Employee Engangement pelanggan adalah dengan mengurutkan nilai 
dari setiap pelanggan dari yang terkecil sampai yag terbesar.

$$
\begin{aligned}
& \text { EE persen } \quad=20,5 / 40=0,51 \text { atau } 51 \% \\
& \text { Median }=3.527 \\
& \text { Mean }=3.542 \text { (lebih besar dari } \\
& \text { median) } \\
& \text { EE Index } \quad=(\text { mean } / 5) \times 6=(3.542 / 5) \\
& \text { x } 6=4.250
\end{aligned}
$$

Dapat dihitung bahwa rata-rata dari 40 data yang didapatkan adalah 3, 542. Karena nilai CE lebih kecil dari 50\%, maka perhitungan nilaiHS adalah :

$$
\begin{aligned}
& \text { HS (persen })=((\text { EE persen } x \text { CL pe:sen }) / 2)^{0,5} \\
& =((0.51 \times 0.49) / Z)^{0,5} \\
& =0.3535 \text { atau } 35.35 \%
\end{aligned}
$$

EE persen sebesar $51 \%$ dan CE persen sebesar 49\%, maka kuadran Human Sigma berada pada kuadran II. Dengan demikian kondisi yang terjadi pada nilai Human Sigma termasuk dalam non optimized atau tidak optimal karena nilai EE dan CE tidak optimal. Koefisien keuangan yang didapatkan adalah sebesar 2,5 atau masuk dalam tingkatan menengah / rata - rata.

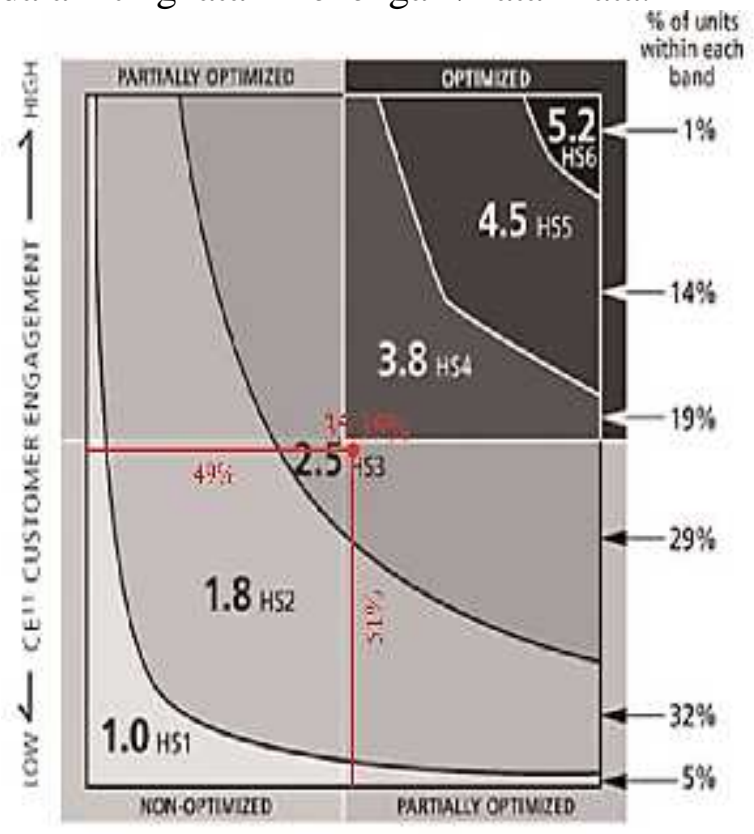

LOW $\longleftarrow$ Q12 EMPLOYEE ENGAGEMENT $\longrightarrow$ HIGH

Gambar 5. Kuadran Human Sigma.

(Sumber : Fleming, 2007)
Dari gambar 5 dapat dilihat bahwa kualitas hubungan antara perusahaan dan karyawan relatif baik karena bernilai $51 \%$, akan tetapi peluang dilakukan perbaikan masih sangat terbuka karena hanya selisih $1 \%$ dari nilai rata - rata, sedangkan kualitas hubungan antara perusahaan dan pelanggannya masih kurang yaitu hanya bernilai $49 \%$ sehingga perbaikan kinerja sangat dibutuhkan. Dengan demikian maka perbaikan akan lebih fokus pada peningkatan hubungan antara pelanggan dan perusahaan, yaitu dengan melakukan peningkatan kualitas pelayanan.

Usaha untuk peningkatan dari kuadran II atau zona partially optimized perlu dilakukan oleh perusahaan dengan membahas variabel yang berpengaruh terhadap ikatan emosional antara ketiga komponen karyawan, pelanggan dan perusahaan agar Human Sigma bisa berada pada kuadran I atau Zona Optimized.

\subsection{Analisis Dimensi Ikatan Emosional Karyawan}

Untuk memperoleh suatu ikatan emosional antara karyawan dan perusahaan terdapat 4 dimensi yang dijadikan sebagai acuan yaitu :

\section{Dimensi "WhatdoIget" as BasicNeed}

Karyawan dituntut paham terhadap tanggung jawab tugasnya dan perusahaan wajib memenuhi fasilitas untuk tercapainya tugas karyawan.

\section{Dimensi "What do I give" as Individual Contribution}

Dimensi kedua yaitu dimensi individual contribution yang menunjukkan tingkat kontribusi setiap karyawan kepada perusahaan, pelanggan, atasan, rekan - rekan kerja.

\section{Dimensi “Do I belong” as Teamwork}

Manajemen harus bisa menciptakan kerjasama diantara karyawan yang baik dan harus bisa menghilangkan ego pribadi dan mementingkan diri sendiri.

\section{Dimensi "How can we grow" as Organic Growth}

Pengembangan diri karyawan harus ditanamkan dalam motivasi kerja sehingga dalam menjalankan tugasnya dilakukan 
dengan penuh tanggung jawab dan bisa bekerja dengan nyaman tidak merasa tertekan dan ada rasa iri pada rekan lain.

\subsection{Analisis Dimensi Ikatan Emosional Pelanggan Dimensi Confidence}

Perusahaan harus menciptakan kepercayaaan karyawan maupun pelanggan melalui pemenuhuan janji, ketepatan waktu, pelayanan sesuai dengan kontrak, kesanggupan untuk menerima komplain pelanggan.

\section{- Dimensi Integrity}

Manajemen harus berani tidak membedakan pelayanan terhadap semua pelanggan karena beda nilai kontrak, status soial dan juga kepada siapa pelayananan diberikan karena kedudukan pelanggan.

\section{- Dimensi Pride}

Manajemen harus membangun kebanggan kepada semua pelanggan melalui sarana prasarana yang dimiliki. Demikian juga kepada para karwaan harus dibuat membanggakan.

\section{- Dimensi Passion}

Dimensi Passion menuntut manajemen bisa menginformasikan pelanggan setia yang berkualitas sebagai media iklan.

\section{KESIMPULAN}

Berdasarkan perhitungan dan analisis didapatkan bahwa Human Sigma berada pada kuadran 2 dan 3. Kondisi ini berarti nilai Human Sigma termasuk dalam non optimized atau tidak optimal dengan nilai HS persen $35,35 \%$. Sedang nilai keeratan hubungan pelanggan (CE) didapat 49\%, sehingga peningkatan nilai $\mathrm{CE}$ menjadi sangat penting bagi Jeng Dewi Wedding Organizer. Sedangkan untuk nilai keeratan hubungan karyawan (EE) yaitu sebesar 51\%, namun harus tetap dilakukan perbaikan.

\section{DAFTAR PUSTAKA}

Fleming, J.H. dan J. Asplund. Human Sigma Managing The EmployeeCustomer Encounter. Gallup Pless, New York, 2007.

Fleming, J.H., C. Coffman dan J.K Harter. Manage Your Human SigmaHardvard Business Review. New York: The Gallup Organization, 2005.

Singarimbun, M. Metode Penelitian Survey. Jakarta : LP3ES, 1989.

Yamin, S., \& Kurniawan, H. SPSS Complete. Jakarta: Salemba Infotek, 2009. 